\title{
LA MUERTE DE LA VÍCTIMA CON OCASIÓN DE UN ATENTADO SEXUAL ${ }^{*}$
}

\section{LUIS RodRÍGUEZ COLlaO ${ }^{* *}$}

\begin{abstract}
RESUMEN: La muerte de la víctima es un acontecimiento que puede acompañar la ejecución de un delito de significación sexual por variadas razones. Desde luego, en la mayor parte de los casos ella sobrevendrá como resultado de la fuerza física utilizada al cometer el hecho delictivo. Sin embargo, en casos excepcionales, ella puede tener su causa en la propia ejecución de la conducta incriminada; en la utilización de cualquier medio de comisión, aunque no sea violento; e incluso, en la impresión que provoca en el ofendido la inminencia del ataque sexual. Varias de las situaciones que pueden llevarse a cabo en la realidad quedan comprendidas en el artículo 372 bis del Código Penal, que sanciona al que comete homicidio con ocasión de la ejecución de un delito de violación. Pero esta disposición no contiene todos los casos en que es posible establecer algún vínculo entre homicidio y violación, ni tampoco aquellos en que la muerte se relaciona con otros delitos de significación sexual, distintos de la violación. El objetivo de este trabajo es examinar, desde una perspectiva dogmática, el tipo penal del artículo 372 bis del Código Penal, con el fin de precisar cuál es su ámbito de aplicación y determinar cómo se resuelven los casos que no quedan comprendidos en esa norma. Todo ello, sin perjuicio de llevar a cabo, también, una valoración crítica del sistema.
\end{abstract}

PALABRAS CLAVE: Proporcionalidad - delito de violación - delito de homicidio - penas - integridad sexual.

Trabajo elaborado en el marco del Proyecto de Investigación FONDECYT 1090195 denominado Protección penal de la vida humana: estudio dogmático y crítico, bajo la dirección de la profesora Dra. María Magdalena Ossandón Widow.

Fecha de recepción: 21 de enero de 2010.

Fecha de aprobación: 15 de junio de 2010.

** Profesor titular de Derecho Penal de la Pontificia Universidad Católica de Valparaíso, Doctor en Derecho por la Universidad de Lérida (EspaÑa). Correo electrónico: lrodrigc@ucv.cl 


\title{
Death of The Victim because of a SeXual Assault
}

\begin{abstract}
The death of a victim is an event that can occur because of the execution of a crime of sexual connotation for several reasons. Of course, in most cases it could happen as a result of the physical effort used to commit the crime. In exceptional cases, however, it could be caused by the proper execution of the incriminating action; in the utilization of any means for its commission, even when not violent; and still in the impression caused in the offended party upon the imminence of a sexual assault. Several of the situations that could actually happen are contained in article 372 bis of the Criminal Code that penalizes anyone committing homicide due to the execution of rape. But this provision does not contain every case in which it is possible to link the homicide to the rape, nor those in which death is related with other crimes of sexual significance, different from rape. The purpose of this article is to examine from a dogmatic point of view, the criminal type of article 372 bis of the Criminal Code, in order to specify what its scope of application is and to determine how those cases not comprehended by the norm are resolved. The previous accompanied by a critical assessment of the system.
\end{abstract}

KEY WORDS: Proportionality - Rape crime - Homicide - Penalty Sexual integrity.

\section{INTRODUCCIÓN}

La muerte de la víctima es un acontecimiento que puede acompañar la ejecución de un delito de significación sexual por variadas razones. Desde luego, en la mayor parte de los casos ella sobrevendrá como resultado de la fuerza física utilizada al cometer el hecho delictivo. Sin embargo, en casos excepcionales, ella puede tener su causa en la propia ejecución de la conducta incriminada (por ejemplo, la introducción del pene, en la violación; o de algún objeto, en el delito de abuso sexual agravado del artículo 365 bis del Código Penal); en la utilización de cualquier medio de comisión, aunque no sea violento (por ejemplo, el suministro de alguna substancia con el propósito de conseguir que la víctima quede privada de sentido), e incluso, en la impresión que provoca en el ofendido la inminencia del ataque sexual.

Varias de las situaciones que pueden darse en el mundo real quedan comprendidas en el artículo 372 bis del Código Penal, que sanciona al que comete homicidio con ocasión de la ejecución de un delito de violación. Pero esta disposición no contiene todos los casos en que es posible 
establecer algún vínculo entre homicidio y violación, ni tampoco aquellos en que la muerte se relaciona con otros delitos de significación sexual, distintos de la violación.

Por otra parte, la disposición aludida no solo es criticable por utilizar la técnica de los delitos complejos -solución normativa que afecta severamente las relaciones de proporcionalidad que uno esperaría ver al interior del Código Penal-, sino además por plantear una serie de dificultades interpretativas que, en muchos casos, redundan en la aplicación de criterios francamente injustos, como lo pone de manifiesto con frecuencia la praxis judicial.

El objetivo de este trabajo es, entonces, examinar dogmáticamente la figura del artículo 372 bis del Código Penal; precisar cuál es su ámbito de aplicación y determinar cómo se resuelven los casos que no quedan comprendidos en esa norma. Todo ello, sin perjuicio de llevar a cabo, también, una valoración crítica del sistema.

\section{1) Antecedentes del aRTículo 372 BIS Del Código Penal}

Esta disposición -que, por cierto, no figuraba en el texto original del Código Penal- fue introducida en el año 1979 como reacción frente a un extraño caso de secuestro con homicidio y supuesto conato de violación de un niño, hecho que alcanzó gran notoriedad a nivel nacional y que hasta hoy suscita numerosas interrogantes. La norma, que pasó a ser el artículo 372 bis de dicho Código, fue agregada por el artículo único (numeral cinco) del Decreto Ley No 2.967, de 11 de diciembre de 1979. Su texto era el siguiente:

Art. 372 bis. El que con motivo u ocasión de violación o de sodomía causare, además, la muerte del ofendido será castigado con la pena de presidio perpetuo a muerte.

Este precepto, como es fácil de suponer, no fue bien recibido por los autores. Las críticas se dirigieron, fundamentalmente, al empleo del verbo causar-que según algunas opiniones convertía a la figura en un delito calificado por el resultado- ${ }^{1}$ y al uso de la locución con motivo, a la cual so-

En este sentido, Garrido Montt, Manuel (1998). Derecho Penal. Parte especial, tomo III, Santiago: Editorial Jurídica de Chile, pp. 329-330, en la versión del año 2005 pp. 330-331. Politoff, S. / Matus, J. P. / Ramírez, M. C. (2005). Lecciones de Derecho Penal. Parte especial, 2a ed., Santiago: Editorial Jurídica de Chile, p. 265. De una opinión contraria, Etcheberry, Alfredo (1998). Derecho Penal, tomo III, Santiago: Editorial Jurídica de Chile, pp. 59-60 y Rodriguez Collao, L. / De la Fuente, F. (1990). "El principio de culpabilidad en la Constitución de 1980", Revista de Derecho, Pontificia Universidad Católica de Valparaíso, No 13, pp. 150-152, quienes se mostraban favorables a la exigibilidad de dolo respecto de esta figura. 
lía atribuirse un alcance demasiado amplio, comprensivo aun de aquellas situaciones en que la muerte estuviera motivada por el interés de violar a la víctima, aunque esto último no se concretara.

El artículo 121 de la Ley No 19.617, de 1999, reemplazó el texto del artículo 372 bis del Código Penal, el que pasó a constar de dos incisos del siguiente tenor:

Art. 372 bis. El que con ocasión de violación cometiere además homicidio en la persona de la víctima, será castigado con presidio mayor en su grado máximo a presidio perpetuo.

El que con ocasión de violación por vía vaginal si la víctima fuere mujer o por vía anal si fuere hombre, cometiere además el homicidio del ofendido será castigado con la pena de presidio perpetuo a muerte.

El cambio tuvo por objeto, en primer término, adaptar la disposición a la nueva fisonomía que adquirieron los delitos sexuales a partir de la entrada en vigencia de esta ley, en cuyo contexto el hombre pasó a ser sujeto pasivo de violación, y superar, por otra parte, las críticas que suscitaba la redacción anterior, para lo cual reemplazó el verbo causar por cometer y suprimió la locución con motivo. Sin embargo, en cuanto a la penalidad de esta figura, el artículo 372 bis introdujo una distinción cuyos fundamentos resultan francamente incomprensibles: si la violación se ejecutaba por vía vaginal, en el caso de la mujer, o por vía anal, en el caso del varón, la sanción aplicable sería presidio perpetuo a muerte; en cambio, si se ejecutaba por una vía distinta, la pena sería presidio mayor en su grado máximo a presidio perpetuo. La distinción no solo resultaba injustificable por el hecho que se hubiera establecido mayor pena para la violación por vía anal en el caso del hombre, que en el caso de la mujer, sino también por el hecho mismo de que se establecieran diferencias entre distintas formas de acceso carnal que en el artículo 361 aparecían equiparadas.

Por último, tras experimentar una modificación en la sanción aplicable -por obra del artículo $1^{\circ}$ No 14 de la Ley No 19.734, de 2001, que eliminó la pena de muerte-, la redacción del precepto nuevamente fue sustituida, esta vez, en virtud del artículo $1^{\circ}$ No 20 de la Ley No 19.927, de 2004. El tenor actual de la disposición, que proviene precisamente de dicha enmienda legal, es el siguiente:

Art. 372 bis. El que, con ocasión de violación, cometiere además homicidio en la persona de la víctima, será castigado con presidio perpetuo a presidio perpetuo calificado. 


\section{2) FUNDAMENTOS DE LA FIGURA}

Si no existiera la disposición del artículo 372 bis del Código Penal, el individuo que cometiera violación y homicidio en un mismo contexto espacio-temporal seguramente sería sancionado con la pena de presidio mayor en su grado medio. Ello en atención a que lo más probable es que se apreciara allí un concurso ideal de delitos y se aplicara ese grado por ser el más alto que prevé tanto el marco penal del homicidio simple como el de la violación propia (artículos 391 No 2 y 361 del Código Penal, respectivamente).

Si la víctima, en cambio, fuera una persona menor de catorce años, la pena probablemente sería la de presidio mayor en su grado máximo, por ser este el grado superior del marco penal asignado al delito de violación impropia, que en tal supuesto asume -paradójica e inexplicablemente, por cierto- la condición de delito más grave, para los efectos del artículo 75 del Código Penal.

Cabe preguntarse, entonces, qué razón habrá tenido en cuenta el legislador para aumentar la pena desde presidio mayor en su grado medio o máximo, según el caso, hasta "presidio perpetuo a presidio perpetuo calificado", para aquellos casos en que la violación y el homicidio afectan a una misma persona y, además, coinciden espacio-temporalmente.

Desde luego, no cabe buscar el fundamento de tal decisión legislativa en el ámbito del resultado, porque el atentado contra la vida de la víctima y el atentado contra su integridad sexual no ven aumentada su gravedad por el hecho de que uno de ellos ocurra con cierta proximidad al otro. Tampoco parece acertado plantear que el fundamento del trato más severo consiste en que la ejecución de uno de esos delitos favorece la ejecución del otro, porque si este fuera el fundamento, pensando en el resultado muerte, la agravación tendría que haberse extendido a todas las hipótesis delictivas que presuponen el empleo de violencia, no solo a la violación; y, por el contrario, el homicidio no puede ser planteado como favorecedor o facilitador de la violación, sencillamente porque ocurrido el primero la segunda se vuelve un delito imposible.

La verdad es que no existe ninguna razón vinculada con el desvalor de acción o de resultado, del homicidio o de la violación, que justifique un trato más severo para la persona que ejecuta ambas acciones en un mismo contexto situacional. Todo lo contrario, es indudablemente más acentuada la ilicitud y más intenso el juicio de reproche que cabe formular a quien viola y mata a una misma persona en oportunidades diversas, o a quien comete violación en contra de un individuo y homicidio respecto de otro, y a pesar de ello estos casos no quedan sometidos al régimen de mayor severidad que prevé el artículo 372 bis del Código Penal. En estas circunstancias, solo cabe reconocer que la figura allí contemplada tiene 
como único fundamento razones de política criminal vinculadas con el propósito de establecer un trato más severo para quien mata con ocasión de una violación, con un claro sentido preventivo-general, al margen de cualquier consideración vinculada con las relaciones de proporcionalidad que deberían existir entre los distintos bienes jurídicos que protege el ordenamiento penal ${ }^{2}$. Por decirlo con otras palabras: corresponde a una decisión arbitraria del legislador.

En estas circunstancias, todo parece indicar que la norma en estudio no cumple los requirimientos mínimos que establece la Constitución para la legitimidad del ejercicio de la potestad punitiva. En relación con este punto, recordemos que el artículo $1^{\circ}$ de la Constitución reconoce el valor de la dignidad humana y lo hace dentro de un capítulo denominado Bases de la institucionalidad. Esto quiere decir que la Carta Fundamental sitúa aquel valor como principio básico del ordenamiento jurídico ${ }^{3}$, y como fuente de legitimidad (pero, al mismo tiempo, como un límite) de la actuación de los poderes públicos; y de modo muy particular, en lo que concierne al ejercicio de la potestad punitiva estatal ${ }^{4}$. Así, pues, la inclusión del concepto de dignidad humana en preceptos autónomos y estrechamente vinculados con la noción de Estado de Derecho, constituye una base normativa que se proyecta sobre todo el ordenamiento jurídico y que no puede ser ignorada por el Poder Legislativo, al momento de formular las leyes; ni por el órgano jurisdiccional, al interpretar y aplicar el derecho positivo; ni, tampoco, por la doctrina al momento de formular sus elaboraciones dogmáticas 5 . Y si lo anterior es válido respecto de todos los sectores del ordenamiento jurídico, lo será en una medida mucho más intensa en relación con el derecho penal, cuyo contenido es el que más estrechamente se vincula con el ámbito de protección inherente a la dignidad de la persona.

2 Según Bullemore, V. / Mackinnon, J. (2005). Curso de Derecho Penal. Parte especial, tomo III, Santiago: LexisNexis, pp. 192-193, "lo que el legislador ha querido sancionar con la extrema severidad con que lo hace es, por decirlo de algún modo, la violación brutal y desalmada, que no solo lesiona la libertad sexual de la víctima, sino que además le quita la vida”.

3 Confiriendo, así a todo el ordenamiento jurídico un sentido propio, y condicionando tanto su interpretación, como su aplicación. Nogueira, H. (1995). "Dignidad de la persona y derechos humanos: Constitución, tratados y ley de amnistía”, en VV. AA: La Dignidad de la Persona, Actas de las XXV Jornadas Chilenas de Derecho Público, tomo II, Valparaíso: Edeval, pp. 51 y ss.

4 En este sentido, entre varios otros, González Pérez, J. (1986). La Dignidad de la Persona, Madrid: Civitas, p. 87, y Ruiz-Giménez Cortés, J. (1984). "Comentarios al artículo 10 de la Constitución”, en Alzaga Villaamil, O. (dir.): Comentarios a las Leyes Políticas, tomo II, Madrid: Edersa, pp. 102 y ss.

5 Bacigalupo, E. (1999). Principios Constitucionales de Derecho Penal, Buenos Aires: Hammurabi, pp. 155-156. 
Pese a las dificultades que existen para atribuir a la noción de dignidad humana un sentido estrictamente jurídico, la doctrina contemporánea afirma unánimemente que aquella locución alude al rango o categoría que corresponde al hombre como ser dotado de inteligencia y libertad, distinto y superior a cualquier otra criatura o realidad. En otras palabras: la superioridad e importancia de que es merecedor el ser humano por el solo hecho de ser tal ${ }^{6}$. De entre las múltiples concreciones que es posible extraer del concepto de dignidad humana, y basándonos únicamente en aquellos puntos que concitan un margen razonable de consenso, podemos visualizar tres aspectos en los cuales aquel se proyecta de modo fundamental: la subjetivización del individuo, su autonomía y su superioridad.

Centrándonos en lo que a estos fines interesa, la subjetivización del individuo implica la necesidad de tratar al ser humano conforme a los caracteres que permiten diferenciarlo de las otras realidades. Es decir, el imperativo de considerarlo y tratarlo como ser dotado de inteligencia, voluntad y libertad. Contradice, en consecuencia, este postulado cualquier actitud -sea que provenga del Estado, de una agrupación o de otro individuo- que instrumentalice a la persona o que desconozca su condición jurídica de sujeto, relegándola al plano de los objetos. Así, la pretensión de utilizar la pena con fines preventivo-generales, es decir, como un medio para obtener por parte del resto de la comunidad que adopte una actitud de adhesión a esos mismos cánones morales, implica, ni más ni menos, que instrumentalizar al individuo en pro de la obtención de un beneficio social (o, mejor dicho, de lo que el poder político considera como tal), con lo cual se vulnera el principio de subjetivización del individuo, un aspecto consubstancial al valor de la dignidad humana, infringiéndose directamente la letra de la Constitución.

Como se señaló anteriormente, la figura de violación con homicidio no se funda en una mayor intensidad de lo injusto o de la culpabilidad, sino exclusivamente en el criterio de necesidad de pena, por haber estimado el legislador que en este caso se requería proceder con la mayor drasticidad, a fin de producir un efecto intimidativo-general. En estas circunstancias, la norma del artículo 372 bis del Código Penal, en cuanto prevé una pena más grave para quien comete homicidio y violación en una relación de proximidad temporal (que la que correspondería aplicar por la

González Pérez (1986) 111-112; Ruiz Miguel, C. (1995). "El significado jurídico del principio de la dignidad de la persona en el ordenamiento español”, en VV. AA: La Dignidad de la Persona, Actas de las XXV Jornadas Chilenas de Derecho Público, tomo II, Valparaíso: Edeval, pp. 101-103 y SÁnchez Agesta, L. (1980). El Sistema Politico de la Constitución Española de 1978, Madrid: Editora Nacional, p. 74. 
comisión de ambos delitos según las reglas generales), implica, ni más ni menos, que instrumentalizar al individuo que debe soportar su aplicación, vulnerando con ello el valor de la dignidad humana y, por ende, el tenor literal de la Constitución.

\section{1) NATURALEZA JURÍdicA de LA FIGURA}

A pesar del planteamiento que aquí hemos formulado en cuanto a la inaplicabilidad del precepto en estudio, conviene que nos preguntemos acerca de la naturaleza jurídica y la estructura interna de la figura que allí se contempla -materias a las que destinaremos el presente acápite y el siguiente-, fundamentalmente en atención a la aplicación práctica que dicho precepto ha venido recibiendo.

Tocante a la primero, algunos plantean que la hipótesis contemplada en el artículo 372 bis del Código Penal corresponde a una figura agravada o calificada de violación, planteamiento que no compartimos ${ }^{7}$. Un delito pasa a ser calificado por el hecho de concurrir algún elemento que le confiere un plus de gravedad, como sucede, por ejemplo, con el homicidio, que adquiere aquella condición cuando el hechor utiliza alguno de los medios de ejecución que menciona el artículo 391 No 1 del Código Penal. Pero ha de tratarse, como es obvio, de un elemento inherente al delito cuya calificación se afirma, es decir, algún factor vinculado con la conducta, con sus medios de ejecución, con la calidad de los sujetos, con los posibles resultados de la acción delictiva, etc. Nada de ello ocurre en el caso que nos ocupa, porque entre acceso carnal y muerte no es posible establecer ninguna forma de relación, que no sea la proximidad temporal. En estas circunstancias, podrá resultar agravada la situación penal del sujeto, pero no la gravedad de alguno de los hechos que la norma contempla ${ }^{8}$.

De ahí, entonces, que en vez de hablar de violación calificada sea preferible utilizar la rúbrica violación con homicidio9; y no al revés, porque

7 Violación agravada la llaman Aguilar Aranela, C. (2008). Delitos sexuales, Santiago: Editorial Metropolitana, p. 68, y Politoff / Matus / Ramírez (2005) 264. Por su parte, Maldonado, F. (2005). “Complemento de actualización”, en Garrido Montt, M.: Derecho Penal. Parte especial, tomo III, Santiago: Editorial Jurídica de Chile, p. 379, se refiere a ella como una figura calificada de violación.

8 Quienes utilizan esta terminología, además, no explican por qué lo agravado sería la violación y no el homicidio, porque en estricto rigor la pena que contempla el artículo 372 bis del Código Penal es superior a la de ambos delitos.

9 Esta denominación -empleada, entre los autores, por Bullemore / Mackinnon (2005) 191 - es la más utilizada por la praxis judicial. Véase por ejemplo la sentencia del Tribunal de Juicio Oral en lo Penal de San Felipe, de 25 de marzo de 2008 (RIT 07-2008 - RUC 0510017796-1) y la sentencia del Tribunal de Juicio Oral en lo Penal de Quillota, de 26 de marzo de 2009 (RUC N: $0800157095-2$ - RIT N: 13-2009). 
como ya se explicó la violación nunca podría estar precedida de un homicidio $^{10}$.

Desde otro punto de vista, la figura de violación con homicidio suele ser planteada como un delito complejo ${ }^{11}$, es decir, una hipótesis delictiva que reúne dos o más conductas que independientemente consideradas de todos modos son constitutivas de delito y cuya importancia dogmática consiste en resaltar la necesidad de que en tales casos se den todos los supuestos típicos que la ley demanda por separado. Pues bien, así entendida la noción de delito complejo, en verdad no existe inconveniente para entender que la figura en estudio pertenece a esa categoría, pero si lo que se pretende manifestar es que ella corresponde a un tipo autónomo, la respuesta habrá de ser exactamente la contraria. Un tipo, en efecto, presupone la existencia de una sustrato valorativo que justifica el merecimiento de pena de la(s) conducta(s) tipificada(s), lo que -como ya se explicó- no se da en este caso; y, por otra parte, en caso de reunirse dos o más conductas en un mismo tipo penal, será menester que entre ellas exista un nexo objetivo o material y uno subjetivo o ideológico que configuran la existencia de una unidad de acción ${ }^{12}$. Sin embargo, como entre violación y homicidio no cabe imaginar ninguna clase de conexión típica, el legislador se limita a exigir una simple relación de proximidad temporal, elemento que claramente resulta insuficiente para concluir que estamos en presencia de una entidad delictiva autónoma.

Por ello, solo cabe concluir que el artículo 372 bis del Código Penal no consagra un tipo, sino una regla de penalidad aplicable a la persona que ha cometido un homicidio y una violación en un mismo contexto situacional. En otras palabras, desempeña el mismo rol que juegan, por ejemplo, las disposiciones contenidas en los artículos 74, 75 y 451 del Código Penal o el artículo 351 del Código Procesal Penal.

\section{2) ELEMENTOS DE LA FIGURA}

La figura requiere, en primer término, que se haya cometido una violación. Sobre el alcance de este último concepto, nos parece claro que este alude tanto al delito contemplado en el artículo 361 del Código Penal (comúnmente denominado violación propia), como al que aparece tipificado en el artículo 362 del mismo Código (que suele recibir el nombre de

10 Con todo, la rúbrica homicidio con violación no es del todo desconocida en el lenguaje judicial. La utiliza, por ejemplo, la sentencia del Tribunal de Juicio Oral en lo Penal de Osorno, de 10 de diciembre de 2009 (RIT 122-2009; RUC 0801152064-3).

11 Ver, por todos, Mercado Gómez, M. A. (2003). Problemas concursales y delito continuado en los delitos que protegen la libertad sexual, Santiago: LexisNexis, p. 76.

12 En este sentido, Künsemüller, C. (2004). "Delitos de hurto y robo: una reforma inaplazable en el Código Penal chileno", en VV. AA: El penalista liberal. Libro de homenaje a la memoria del profesor Manuel de Rivacoba y Rivacoba, Buenos Aires: Hammurabi, p. 470. 
violación impropia), básicamente porque ambos preceptos figuran bajo un mismo epígrafe que utiliza aquella denominación.

Por el contrario, no cabe incluir bajo la rúbrica violación las conductas tipificadas en el artículo 365 bis del Código Penal, pese a que estas aparecen prácticamente equiparadas a aquel delito en cuanto a los márgenes de penalidad, porque ellas en verdad corresponden a una forma específica del delito de abuso sexual. A esta conclusión se llega tras considerar que -para referirse a la conducta sancionada- aquel artículo utiliza la fórmula "acción sexual", la que aparece definida en el artículo 366 ter del mismo Código como cualquier acto de significación sexual y de relevancia, distinto del acceso carnal, realizado mediante contacto corporal con la víctima, o que haya afectado los genitales, el ano o la boca de la víctima. Sin embargo la misma disposición señala el ámbito de aplicación de esta definición, el que queda circunscrito a "los tres artículos anteriores", es decir, los artículos 365 bis, 366 y el 366 bis. Es por esta razón que la mayor parte de la doctrina entiende que la figura contemplada en el primero de los preceptos recién mencionados no pertenece al ámbito de la violación, sino al del abuso sexual, recibiendo, por lo general, la denominación de abuso sexual agravado o cualificado ${ }^{13}$.

Se exige, enseguida, que el autor haya cometido homicidio, expresión que debemos entender como causación de la muerte en un contexto delictivo. En otras palabras, dicho vocablo debe ser apreciado como un elemento normativo del tipo y no como un elemento descriptivo. Para llegar a esta conclusión basta considerar que el texto original del artículo 372 bis utilizaba la fórmula "causare la muerte" y que esta fue sustituida por "cometiere homicidio", precisamente para evitar que dicha norma operara como delito calificado por el resultado. En consecuencia, una interpretación literal del precepto, corroborada por sus antecedentes históricos, lleva necesariamente a concluir que este no incluye los casos en que la víctima de violación muere por causas fortuitas o meramente accidentales.

También queda excluida la muerte atribuible a culpa ${ }^{14}$, porque si bien esta puede calificarse de homicidio, según el léxico que utiliza el Código Penal, no debemos olvidar que las acciones que tipifica dicho texto normativo solo admiten una forma de ejecución dolosa, salvo que la propia redacción de un precepto utilice alguna expresión de la cual pueda

13 En este sentido, Bullemore / Mackinnon (2005) 201; Politoff / Matus / Ramírez (2005) 271, y Rodríguez Collao, L. (2008). "La figura cualificada de abuso sexual del artículo 365 bis del Código Penal", en VV. AA: Delito, pena y proceso. Libro homenaje a la memoria del profesor Tito Solari Peralta. Santiago: Editorial Jurídica de Chile, pp. 357-380. Disiente de este planteamiento Fernández Cruz, J. A. (2004). "Una interpretación racional del nuevo artículo 365 bis del Código Penal”, Doctrina Procesal Penal (Colección informes en Derecho, Defensoría Penal Pública).

14 Así opinan también, Aguilar Aranela (2008) 69 y Bullemore / Mackinnon (2005) 191. 
inferirse la voluntad de sancionar la ejecución imprudente de una determinada conducta. A lo anterior cabe agregar un antecedente de índole formal: que los tipos culposos previstos en los artículos 490 y siguientes del Código Penal, solo se refieren a los delitos contra las personas y la violación con homicidio en el ordenamiento jurídico chileno no está contemplada en el Título que dicho Código destina a esos delitos, sino en el apartado referente a los delitos que atentan contra la integridad sexual.

Respecto del homicidio simple, del homicidio calificado y del parricidio basta con señalar que estas figuras aparecen contempladas en un mismo párrafo bajo la rúbrica Del homicidio, para concluir que todas ellas quedan incluidas dentro de los términos que utiliza el artículo 372 bis del Código Penal; de manera que la norma capta, por ejemplo, tanto el hecho de que un padre viole y mate a su hija, como el hecho de que alguien viole y mate a una persona concurriendo alguna de las circunstancias que contempla el artículo 391 No 1 , como el hecho de que alguien viole y cometa homicidio, sin que concurra alguna de esas mismas circunstancias. Corrobora esta afirmación el hecho de que la pena establecida en aquel artículo es siempre superior a la que el Código Penal contempla para los delitos de homicidio simple, homicidio calificado y parricidio.

Ahora bien, entre violación y homicidio debe existir un vínculo que la norma refiere como una exigencia de que el homicidio se cometa con ocasión del delito de violación y que la mayor parte de los autores califica como de proximidad o inmediatez temporal ${ }^{15}$. Sobre esta base, algunos de ellos sostienen que la muerte puede inferirse para ocultar el delito o eludir la responsabilidad ${ }^{16}$. Esa locución, sin embargo, posee un campo semántico mucho más reducido de lo que ella a simple vista parece indicar. En efecto, si la voz homicidio tiene un sentido jurídico, también tendrá que poseer la misma índole cualquier referencia que involucre o concierna a dicho concepto. Por ello, no basta con que la violación y el homicidio se sitúen próximos en el tiempo, sino que será necesario que el segundo ocurra con ocasión de actos que impliquen -jurídicamente hablando- ejecución o comienzo de ejecución de la primera ${ }^{17}$. Por el contrario, no se daría el vínculo exigido por la norma si la muerte ocurre una vez consumada la violación (por ejemplo a raíz de una discusión suscitada entre autor y víctima) o si se produce al percatarse el autor que la víctima se dirige a un centro policial a estampar una denuncia ${ }^{18}$.

15 Por todos, Bullemore / Mackinnon (2005) 191.

16 De esta opinión, Garrido Montt, M. (2005) 330-331 y Bullemore / Mackinnon (2005) 191.

17 Entiendo que esta es también la posición que sustenta Maldonado (2005) 379, al afirmar que "con ocasión de la violación”, significa "dentro del contexto fáctico de su ejecución".

18 Desafortunadamente, la jurisprudencia no siempre lo ha entendido así y hay fallos que aplican la pena contemplada en el artículo 372 bis del Código Penal, aunque el homicidio tenga su principio de ejecución en un hecho ocurrido con posterioridad a la consumación de la 
La aplicación de la pena establecida en el artículo 372 bis del Código Penal presupone que tanto la violación como el homicidio se encuentren consumados $^{19}$. Ello obedece al empleo de la fórmula discursiva "cometiere además homicidio", la cual implica que tanto este último delito como la violación deben encontrarse cometidos, es decir, consumados ${ }^{20}$. Por esta misma razón y porque en estricto rigor aquella disposición no contiene un tipo sino una regla de penalidad, no cabe hablar de tentativa o de delito frustrado de violación con homicidio. De manera que si al violar a la víctima, el autor le causa dolosamente lesiones letales, pero la muerte no se produce, el título de la imputación será violación en concurso con homicidio frustrado (o, en su caso, con tentativa de homicidio).

Asimismo, la pena prevista por el artículo 372 bis del Código Penal solo puede ser impuesta a quien intervenga como autor en los dos hechos que la norma describe, descartándose su aplicación en caso de que la intervención de una persona se limite a uno solo de tales hechos y también cuando un individuo toma parte como autor en uno y como partícipe en el otro. Ello obedece a que el precepto que comentamos exige que la violación y el homicidio hayan sido cometidos por la persona que debe soportar el castigo y en el lenguaje coloquial se entiende que comete un acto quien lo ejecuta en forma directa y personal. Queda descartada, en consecuencia, la posibilidad de aplicar las penas previstas en aquel artículo a quien haya tenido intervención como autor mediato o partícipe, aunque haya tenido injerencia tanto en el homicidio como en la violación ${ }^{21}$.

Sabido es que el sujeto pasivo del delito de violación es tanto el hombre como la mujer, pues así lo deja claramente establecido el art. 361 inciso segundo del Código Penal al utilizar el vocablo persona. El sujeto activo, en cambio, solo puede ser un varón, lo cual deriva de que la conducta típica aparece señalada, en ese mismo precepto, con la fórmula verbal acceder carnalmente, comportamiento del que solo es capaz una persona de sexo masculino ${ }^{22}$. Estos planteamientos, desde luego, también son

violación, como sucede, por ejemplo, en un fallo del Tribunal de Juicio Oral en lo Penal de San Felipe, de 25 de marzo de 2008 (RIT 07-2008 RUC 0510017796-1).

19 En este mismo sentido, Aguilar Aranela (2008) 69-70.

20 La sinonimia que es posible establecer entre cometer y consumar, en el lenguaje coloquial, aparece refrendada por numerosos diccionarios. Por citar algunas de las páginas electrónicas que registran estos fenómenos puede verse: http://www.wordreference.com; http://www. elmundo.es/diccionarios/; http://www.lenguaje.com/herramientas/tesauro.php; http://www. sinonimia.net/ y http://www.diccionarios. com/consultas.php

21 De una opinión distinta, Aguilar Aranela (2008) 70, quien sostiene que la autoría mediata y la instigación tienen cabida en la figura que nos ocupa.

22 Por todos, en este mismo sentido: Carrasco Jiménez, E. (2007). "El problema del sujeto activo del delito de violación y sus posibles vacíos legales, Ius et Praxis, año 13, No 2, pp. 137-155, y Rodríguez Collao, L. (2004). Delitos sexuales, Santiago: Editorial Jurídica de Chile, pp. 142-145. De una opinión distinta, Carnevali, R. (2001). "La mujer como 
aplicables a la figura que contempla el artículo 372 bis del Código Penal, en cuanto exige que se haya cometido una violación.

Por otra parte, no debemos pasar por alto que todos los atentados en contra de los intereses sexuales de una persona suponen que la víctima se encuentre con vida al momento de ejecutarse la acción constitutiva de tales delitos. De modo que si el agresor mata a un individuo para cometer alguna forma de aberración sexual con su cadáver o si comete tal aberración en el cadáver de la persona de quien originalmente pretendía abusar en vida, el atentado sexual no se configura, sencillamente porque el bien jurídico no existe ${ }^{23}$. En tales circunstancias faltará uno de los supuestos necesarios para que se configure la hipótesis prevista en el artículo 372 bis del Código Penal.

Por último, a diferencia de lo que sucede en otras figuras análogas, esta disposición exige que una misma persona asuma la condición de víctima tanto del homicidio como de la violación. Así se desprende del hecho de que la norma exija que el primero recaiga "en la persona de la víctima" (de la violación). De manera que no corresponde aplicar el artículo 372 bis del Código Penal si el sujeto pasivo del ataque sexual sobrevive, pero muere -a manos del agresor- quien acude en auxilio de aquel.

En relación con los aspectos subjetivos de la disposición que comentamos, cabe señalar que tanto la violación como el homicidio deben cometerse dolosamente. En consecuencia, será necesario que el sujeto activo haya actuado con voluntad de acceder carnalmente a la víctima y con voluntad de matarla. Ello no quiere decir, sin embargo, que ambas voluntades deban existir desde que comienza la actuación del individuo. En efecto, el núcleo de la figura es la violación, de modo que lo único que cabe exigir desde el inicio, es el ánimo de llevar a cabo el acceso carnal. El propósito de matar, en cambio, puede surgir con posterioridad -por ejemplo, motivado por el curso que toman los acontecimientos-, situación que es perfectamente compatible con el empleo de la fórmula "con ocasión", que alude a la muerte que tiene lugar durante la ejecución de aquel delito.

Puesto que el artículo 372 bis del Código Penal no contempla ninguna referencia de orden subjetivo, debemos entender que tanto el homicidio como la violación a que alude este precepto pueden ser ejecutados, indistintamente, con dolo directo o eventual ${ }^{24}$. Este planteamiento, que

sujeto activo en el delito de violación. Un problema de interpretación teleológica”, Gaceta Jurídica, No 250, abril, pp. 13-18, y MaLdonado (2005) 355-356.

23 De la misma opinión, en relación con el Derecho espańol, entre muchos otros, Monge Fernández, Antonia (2005). Los delitos de agresiones sexuales violentas, Valencia: Tirant lo Blanch, p. 63, y Orts Berenguer / Suárez-Mira Rodríguez (2001). Los delitos contra la libertad e indemnidad sexuales, Valencia: Tirant lo Blanch, p. 30. Basado en el Derecho argentino, Buompadre, J. (2003). Derecho Penal. Parte Especial, 2a ed., Buenos Aires: Mario 
es prácticamente unánime respecto del homicidio, no suscita el mismo nivel de consenso en el caso de la violación, que según algunos autores solo podría ser cometido con dolo directo ${ }^{25}$. Si bien es cierto que la conducta principal de este delito, es decir, el acceso carnal, solo es concebible en un contexto de actuación en que el individuo dirige su comportamiento hacia el logro de ese objetivo, no debemos olvidar que hay otros componentes del hecho respecto de los cuales sí es concebible su aceptación como algo de ocurrencia simplemente probable, como, por ejemplo, el hecho de ser la víctima menor de catorce ańos. Esta afirmación aparece corroborada por la circunstancia de que en otras extremos del delito de violación el Código Penal exija una actuación "abusiva" -lo que solo puede significar una exigencia de dolo directo-, como sucede, por ejemplo, en las hipótesis contempladas en los numerales $2^{\circ}$ y $3^{\circ}$ del inciso segundo del artículo 361 .

Un grupo minoritario de autores considera que, además del dolo, el delito de violación exige la concurrencia de un elemento subjetivo del tipo consistente en un ánimo libidinoso o propósito de obtener una satisfacción sexual ${ }^{26}$. En nuestro concepto, el solo hecho que el tipo de violación no contenga una exigencia especial en tal sentido, es motivo suficiente para descartar la pretensión de incluir por vía interpretativa un elemento que la ley no demanda (restringiendo de ese modo, injustificadamente, el ámbito de protección de los intereses sexuales del individuo $)^{27}$. Corrobora este planteamiento el hecho de que otros tipos del mismo título -entre ellos, algunos que fueron creados o modificados por la misma Ley No 19.617, de 1999, que reestructuró la violación- sí contengan exigencias de orden subjetivo, como, por ejemplo, la figura contemplada en el artículo 366 quater, la cual requiere que el individuo actúe "para procurar su excitación sexual o la excitación sexual de otro".

25 En este sentido, Bullemore / Mackinnon (2005) 191.

26 De esta opinión, en España, Serrano Gómez / Serrano Maillo (2006). Derecho Penal. Parte especial, $11^{\mathrm{a}}$ ed., Madrid: Dykinson, p. 213. En contra, entre varios otros, Cugat Mauri, M. (2004). "Delitos contra la libertad e indemnidad sexuales", en Córdoba Roda / García Arán (dirs.): Comentarios al Código Penal. Parte especial, tomo I, Madrid: Marcial Pons, pp. 315-316; Monge Fernández, A. (2005). Los delitos de agresiones sexuales violentas, Valencia: Tirant lo Blanch, pp. 113-116 y Muñoz Conde, F. (2007). Derecho Penal. Parte especial, 16 ${ }^{\mathrm{a}}$ ed., Valencia: Tirant lo Blanch, p. 217. En la doctrina italiana prima el criterio que considera esta clase de infracciones como delitos de tendencia, y en razón de ello es común que se postule la exigibilidad de una motivación lasciva. Véase CAdoppi, A. (1996). "Commentario", en Alberto Cadoppi (Coord.): Norme contro la violenza sessuale (legge 15 febbraio 1996), Padova: Edit. Dedam, p. 20, y Рiсотті, L. (1996): "Il delito sessuale: ...Spinti di reflessione sull'evoluzione e la riforma dei reati sessuali”, en Alberto Cadoppi (Coord.): Norme contro la violenza sessuale (legge 15 febbraio 1996), Padova: Edit. Dedam, pp. 420-421.

27 Criterio que ha seguido la jurisprudencia, como en la sentencia del Tribunal de Juicio Oral en lo Penal de Ovalle, de 14 de febrero de 2005, en Revista Procesal Penal $\mathrm{N}^{\circ}$ 32, febrero 2005, pp. 210-227. 
El argumento de que el pretendido ánimo lascivo es normalmente inherente a la propia naturaleza del acto sexual, no resulta admisible, porque los casos excepcionales en que el acceso carnal es realizado por otras motivaciones (por ejemplo, venganza, el simple interés de humillar a la víctima o la pretensión de demostrar hombría frente a un grupo) e incluso los casos en que la ejecución de aquel comportamiento produzca desagrado (como cuando el sexo de la víctima no se corresponde con la orientación sexual del hechor), también aparecen captados por los términos acceder carnalmente, con que la ley describe la conducta, de modo que excluirlos del ámbito de la punición significa, lisa y llanamente, interpretar esas expresiones en contra del sentido que claramente fluye de su texto $^{28}$.

\section{3) CirCunstanCias MODifiCATORIAS DE RESPONSABILIDAD PENAL}

Respecto de algunos de los delitos que atentan contra los intereses sexuales del individuo, el artículo 368 del Código Penal concede efecto agravatorio al hecho de ser el autor del delito "autoridad pública, ministro de un culto religioso, guardador, maestro, empleado o encargado por cualquier título o causa de la educación, guarda, curación o cuidado del ofendido". Sin embargo, esta misma disposición señala que ella es aplicable únicamente cuando el título de castigo es alguno de los delitos previstos "en los dos párrafos anteriores", lo cual excluye la posibilidad de aplicar la circunstancia agravante que ella contiene cuando el tribunal aplique la pena prevista en el artículo 372 bis del Código Penal. Por idéntica razón ha de rechazarse la posibilidad de aplicar la circunstancia agravante prevista en el artículo 371 del mismo Código, que castiga como autores a "los ascendientes, guardadores, maestros y cualesquiera personas que con abuso de autoridad o encargo, cooperaren como cómplices a la perpetración de los delitos comprendidos en los dos párrafos precedentes".

Puede suscitar dudas la posibilidad de aplicar en este caso la agravante contemplada en el artículo 12 No 18 del Código Penal, esto es, la de "ejecutar el hecho con ofensa o desprecio del respeto que por la dignidad, autoridad, edad o sexo mereciere el ofendido, o en su morada, cuando él no haya provocado el suceso". Por lo que concierne al respeto por la edad del ofendido, cabe recordar que una de las hipótesis constitutivas de violación

28 Tampoco parece correcto descartar la exigencia de aquel ánimo lascivo, como lo hace CARmona Salgado (2005). "Delitos contra la libertad e indemnidad sexuales (I)", en Cobo del Rosal (Coord.): Derecho Penal español. Parte especial, Madrid: Dykinson, p. 250, argumentando que este "ya se encuentra abarcado por el dolo del agente", porque para que tal cosa fuera efectiva se requeriría que el tipo contuviera una exigencia de orden objetivo, a la cual referir el conocimiento y la voluntad inherentes a dicho componente subjetivo, lo que, por cierto, tampoco se da en el tipo de violación. 
exige que la víctima sea menor de doce años y la mayor penalidad que ella ostenta puede entenderse fundada -si bien no de modo exclusivo, porque también entran en juego otros factores- en la desconsideración con que actúa el delincuente por la situación personal de la víctima ${ }^{29}$. Así, dada la amplitud de la referencia que contiene el artículo 372 bis-que incluye tanto la violación del artículo 361, como la del artículo 362- debemos entender que una agravación de la pena contemplada en el primero de los artículos nombrados, basada en esa circunstancia, vulneraría lo dispuesto por el artículo 63 del Código Penal.

Por lo que atañe, ahora, al respeto que el ofendido mereciere en razón de su sexo, la doctrina siempre entendió que la circunstancia era inherente al delito de violación, en la medida en que este contemplaba como único sujeto pasivo a la mujer. En cambio, frente a la equiparación de ambos sexos en la actual estructura de los tipos de violación, y aunque nadie podría razonablemente postular que la agravante es aplicable en el caso de la violación de un hombre, sí podría pensarse que ella es admisible cuando la víctima sea una mujer. Este planteamiento, sin embargo, no resulta coherente en el contexto de un ordenamiento jurídico respetuoso del valor de la dignidad humana, una de cuyas bases esenciales es la proscripción de cualquier forma de trato discriminatorio; ni resulta compatible con la voluntad legislativa de propender a una total equiparación entre el hombre y la mujer, en lo que respecta a la protección de los intereses de índole sexual.

En relación con la ofensa al respeto que por su dignidad mereciere una persona, tal expresión no está tomada en el sentido de dignidad personal, es decir, como atributo que corresponde a todo ser humano por el solo hecho de ser tal, sino que alude a la cualidad de dignatario, es decir, a la posición de especial relevancia y respetabilidad social de que suelen estar investidas algunas personas. Desde esta perspectiva, no hay inconveniente para aplicar la agravante cuando la víctima se encuentre en la posición descrita, como tampoco lo hay para aplicarla cuando la falta de consideración se refiera al carácter de autoridad o a la morada de la víctima.

En relación con la agravante del No 6 del art.12, esto es, la de "abusar el delincuente de la superioridad de su sexo, de sus fuerzas o de las armas, en términos que el ofendido no pudiera defenderse con probabilidades de repeler la ofensa", no cabe duda que ella resulta incompatible con la hipótesis prevista en el artículo 372 bis del mismo Código, pues en ella subyace la idea de una posición de inferioridad de la víctima en relación

29 Criterio que ha tenido respaldo jurisprudencial, como puede verse en la sentencia del Tribunal de Juicio Oral en lo Penal de Los Vilos, de 28 de julio de 2001, en Boletín del Ministerio Público $\mathrm{N}^{\circ} 4$, agosto 2001, pp. 39-42. 
con el hechor. Ni siquiera es posible estimar dicha agravante cuando sean varios los autores del delito, y pese a que esto indudablemente aumenta el grado de indefensión de la víctima, porque en tales casos no se da un elemento distinto de aquellos que quedan comprendidos dentro de las hipótesis que configuran aquella posición de inferioridad, como, por ejemplo, la violencia, la intimidación o la imposibilidad de resistir.

Ninguna de las situaciones contempladas en el artículo 391 No 1 del Código Penal puede operar con efecto agravatorio de la pena prevista en el artículo 372 bis del mismo Código. En efecto, todas ellas forman parte de la descripción típica del homicidio calificado, y este junto con el homicidio simple y el parricidio, como ya se explicó, quedan comprendidos dentro del campo semántico de la voz "homicidio" que utiliza el segundo de los artículos mencionados. Ello obedece a que en este caso es aplicable la norma contenida en el inciso primero del artículo 63 del Código Penal, que impide conceder efecto agravatorio a las circunstancias que la ley ha tomado en consideración al describir un delito, como ocurre efectivamente en este caso ${ }^{30}$.

Cuando se trata de la alevosía, la conclusión anterior es aplicable tanto respecto de aquellas formas de actuación alevosa que aparecen captadas por la circunstancia genérica del artículo 12 No 1 del Código Penal, como de aquellas otras que aparecen captadas por las modalidades específicas de alevosía previstas en otros numerales del mismo artículo, como es el caso, por ejemplo, del empleo de disfraz (numeral $5^{\circ}$ ) o la ejecución del delito de noche o en lugar despoblado (numeral 12). Todas estas situaciones están incluidas dentro del concepto de alevosía que utiliza el artículo 391 No 1 del Código Penal y, en tal virtud, no pueden operar con efecto agravatorio de la pena contemplada en el artículo 372 bis del mismo Código ${ }^{31}$.

Un planteamiento análogo cabe formular respecto de la posibilidad de que el parentesco o el vínculo matrimonial operen como agravantes, tomando en consideración que esas relaciones forman parte del tipo de parricidio, el que también está incluido dentro de la referencia al homicidio que hace la disposición que motiva estos comentarios.

30 Hay quienes plantean que la improcedencia de aplicar algunas tales agravantes obedece a que ellas operan únicamente en los delitos que atentan contra la personas, en circunstancias que el artículo 372 bis del Código Penal se encuentra ubicado entre los delitos que atentan contra la integridad sexual. En este sentido se pronunció una sentencia de la Corte Suprema de 19 de marzo de 2003 (Rol No 2494-02), con un interesante voto de minoría que critica esta forma de argumentar a la que califica de "formalista y carente de toda sustancia".

31 Por este motivo, no compartimos el criterio adoptado en la sentencia del Tribunal de Juicio Oral en lo Penal de Osorno de 10 de diciembre de 2009 (RIT 122-2009; RUC 0801152064-3), que aplica la agravante del artículo 12 No 12 del Código Penal, a pesar de que el fallo reconoce expresamente que dicha circunstancia "constituye una forma específica de alevosía”. 
Por último, acerca de la atenuante del No 3 del art. 11 del Código Penal, esto es, "la de haber precedido inmediatamente de parte del ofendido, provocación o amenaza proporcionada al delito", si bien es inimaginable una actuación encuadrable en la figura en estudio motivada por una amenaza previa, no cabe decir lo mismo de la provocación, que sí puede transformarse en el factor desencadenante de un ataque de esta índole. Y aunque el ordenamiento jurídico chileno no contempla una cláusula eximitoria de responsabilidad que permita albergar una situación de inexigibilidad como la descrita, sí, al menos, le concede efecto aminorante, a condición de que la actitud provocativa de la víctima haya sido proporcionada al delito, es decir, de una intensidad tal que lograra excitar la libido del hechor hasta el punto de que este reaccionara en la forma en que lo hizo.

\section{4) RELACIONES CONCURSALES}

Pueden surgir dudas acerca de la procedencia de aplicar el artículo 372 bis del Código Penal cuando los hechos que esta norma describe aparecen acompañados de otras conductas delictivas. Es lo que sucede, por ejemplo, cuando el sujeto activo, además de violar y matar a la víctima, ha robado cosas que pertenecen a ella o que se encontraban a su cuidado. Enfrentados a esta situación los tribunales en ocasiones han declarado que debe sancionarse a título de robo con homicidio, en concurso con un delito de violación ${ }^{32}$; y en otras oportunidades han declarado que en la medida que a la figura de robo con violencia en las personas se agregue la violación de la víctima y el homicidio de ella, "dichos males precisamente configuran el tipo previsto en el artículo 433 No 1 del Código Penal"33.

Compartimos plenamente esta última afirmación, porque el artículo recién mencionado utiliza las expresiones homicidio y violación en singular, y desprovistas de determinantes; con ello, desde un punto de vista lingüístico-discursivo le atribuye un sentido polivalente que permite captar la comisión de un número indeterminado de homicidios y de violaciones, como así también conductas constitutivas de uno y otro delito. Este planteamiento se ve corroborado por el empleo de la expresión "las víctimas", en el artículo 433 No 2, la cual es claramente demostrativa de que los resultados conexos al robo que menciona esta disposición pueden afectar a más de una persona.

En estas circunstancias, solo cabe extraer dos conclusiones: primero, que utilizar como título de castigo el artículo 433 (para castigar el robo y el homicidio) y además el artículo 361 (para castigar la violación) vulnera

Así lo declaró la Corte Suprema en sentencia de 14 de noviembre de 2000, Rol No 2.860-00.

Sentencia de la Corte Suprema de 17 de enero de 2001, Rol No 2146-00. 
lo dispuesto por el inciso primero del artículo 63 del mismo Código Penal; y, segundo, que entre el artículo 372 bis (que contempla la violación y el homicidio) y el artículo 433 (que contempla el robo, la violación y el homicidio) hay un concurso aparente de leyes penales que debe ser solucionado aplicando este último título en razón de su especialidad. No obsta a la conclusión anterior el hecho de que el límite inferior del marco penal que contempla el artículo 433 No 1 es inferior al del artículo 372 bis (coincidiendo en el límite superior), porque la relación de especialidad se funda en un criterio lógico y no en consideraciones axiológicas, de modo que la norma aplicable puede ser más severa que la norma que resulta desplazada (como ocurre en el binomio homicidio simple-parricidio) o menos severa que esta (como sucede en la relación parricidio-infanticidio).

Por otra parte, es posible que la víctima se encuentre embarazada al momento de sufrir el ataque y que, en tales circunstancias, se produzca la muerte del ser en gestación, ya como resultado de la propia acción delictiva, ya como consecuencia de los medios ejecutivos utilizados o bien a raíz de su escaso nivel de desarrollo físico. En estos casos se configura un concurso ideal entre la figura de violación con homicidio y el delito de aborto de los artículos 342 ó 343 del Código Penal, dependiendo de si hay dolo directo o eventual respecto de la muerte del hijo ${ }^{34}$. Si este último resultado solo es atribuible a título de culpa, el aborto ha de quedar impune.

Centrándonos, ahora, en aquellas situaciones que no quedan comprendidas en el artículo 372 bis del Código Penal, cabe preguntarse, en primer término, cómo debemos proceder cuando la muerte ocurre a consecuencia de una actuación culposa del autor de la violación. La posición mayoritaria entre los autores considera que en este caso estamos en presencia de un concurso ideal de delitos, si bien hay una posición minoritaria que concibe esta situación como un concurso material de delitos $^{35}$. Para estos casos, y para aquellos en que el homicidio sea ejecutado con ocasión de otro delito que no sea el de violación -por ejemplo, abuso sexual- no cabe proponer una fórmula de solución homogénea: se configurará un concurso ideal o un concurso material de delitos, dependiendo de si los actos ejecutados pueden calificarse como un solo hecho, según lo exige el artículo 75, o si, por el contrario, corresponden a hechos independientes, en cuyo caso la pena habrá de determinarse conforme a las pautas del artículo 74 .

34 Entendemos que Aguilar Aranela (2008) 72, discrepa de este planteamiento al afirmar -en referencia al artículo 372 bis del Código Penal- que "Cuando se cometan otros delitos en el mismo contexto situacional, por el desvalor que este crimen lleva implícito, serán todos ellos absorbidos por éste".

35 De acuerdo con la posición mayoritaria, Aguilar Aranela (2008) 69 y Politoff / Matus / Ramírez (2005) 264-265. Sustenta la otra posición, Maldonado (2005) 378. Ver, en este último sentido, sentencia de la Corte Suprema de 5 de agosto de 2008, Rol No 880-08. 


\section{5) ConSECUENCIAS de LA APLICACIÓN DE LA FIGURA}

La existencia de la figura de violación con homicidio trae consigo una serie de consecuencias francamente inaceptables desde la perspectiva de los criterios de proporcionalidad que debería albergar el sistema. Así, por ejemplo, resulta incomprensible que el hecho de matar a una persona y de violar a otra (en oportunidades distintas) sea castigado con menor severidad que el hecho de matar y violar a un individuo en un mismo contexto situacional: en el primer caso, el límite de pena para cada delito es de cinco ańos y un día; en el segundo, presidio perpetuo. Tampoco es comprensible que reciba mayor pena el hecho de matar a la víctima de violación, que el hecho de matar a la persona que acude en defensa de la persona que está siendo violada. Porque en los dos casos que aquí hemos destacado los rangos mayores de penalidad están reservados para situaciones en que existe unidad de víctima; en tanto que los rangos menores lo están para situaciones en que hay dos personas victimizadas: una que fallece $y$ otra que sobrevive tras ser agredida sexualmente.

Por otra parte, la pena que establece el artículo 372 bis del Código Penal (presidio perpetuo a presidio perpetuo calificado) resulta de una severidad francamente inexplicable si se la compara con la pena que merecerían otras conductas muchísimo más graves. Piénsese, por ejemplo, que si un individuo mata a tres personas en un mismo contexto de actuación ("un solo hecho", como dice el artículo 75 del Código Penal), aquel individuo tendrá que soportar la pena mayor asignada al delito más grave, es decir, presidio mayor en su grado medio, si estamos a nivel del homicidio simple. Asimismo, si las acciones las ejecuta en distintos contextos de actuación, seguramente resultará aplicable, por ser más beneficioso, el artículo 74 del mismo Código, que en ningún caso permitiría llegar a una pena perpetua. En estas circunstancias, nadie podría razonablemente explicar por qué un homicidio, por el solo hecho de estar precedido de una violación, debe merecer más pena que tres homicidios.

Por último, entre varios otros ejemplos de falta de proporcionalidad que podríamos señalar, piénsese que la pena prevista en el artículo 372 bis del Código Penal solo es aplicable cuando el homicidio ocurre con ocasión de una violación, no de una conducta calificable como abuso sexual. Ello, a pesar de que hay modalidades de abuso sexual -las que contempla el artículo 365 bis, por ejemplo- que tienen asignada una pena equivalente a la del delito de violación. En estas circunstancias, no se comprende por qué esta asimilación no se hace extensiva también a las situaciones en que la agresión sexual lleva aparejado el homicidio de la víctima. 


\section{CONCLUSIONES}

a) La figura que contempla el artículo 372 bis del Código Penal no corresponde a un tipo, sino a una regla de penalidad aplicable a la persona que ha cometido una violación y un homicidio en un mismo contexto situacional.

b) Esta disposición tiene como único fundamento razones de política criminal vinculadas con el propósito de establecer un trato más severo para el homicidio que ocurre con ocasión de una violación, con un claro sentido preventivo-general, sin implicar un incremento de lo ilícito o de la culpabilidad.

c) En estas circunstancias, la aplicación de la pena prevista en el artículo 372 bis del Código Penal a quien ha cometido un homicidio y una violación, es una forma de instrumentalizar al individuo, lo que pone de manifiesto su inconstitucionalidad.

d) En caso de estimarse -en contra de lo que aquí se sostiene- que la figura de violación con homicidio es aplicable, habrá de tenerse en cuenta que el término violación alude indistintamente al delito del artículo 361, como al tipo contemplado en el artículo 362, ambos del Código Penal, pero no se hace extensiva a las hipótesis previstas en el artículo 365 bis del mismo Código.

e) En el mismo supuesto anterior, habrá de tenerse presente, además, que la figura solo es aplicable cuando el acceso carnal y la muerte se encuentren consumados; que solo podría ser aplicada al autor de tales conductas y que no tienen vigencia respecto de ella las circunstancias agravantes que el Código Penal utiliza al describir el delito de homicidio calificado. Estos planteamientos tienen validez sea que miremos la figura como un delito independiente, sea que la consideremos una regla de penalidad.

f) Tanto en razón de su falta de fundamentos, como en atención a los excesos a que puede conducir y a las consecuencias francamente inaceptables que trae consigo desde la perspectiva de los criterios de proporcionalidad, resulta evidente la necesidad de proceder a la derogación de la figura contemplada en el artículo 372 bis del Código Penal.

\section{BIBLIOGRAFÍA}

- Aguilar Aranela, C. (2008). Delitos sexuales, Santiago: Editorial Metropolitana.

- Bacigalupo, E. (1999). Principios Constitucionales de Derecho Penal, Buenos Aires: Hammurabi.

- Bullemore, V. / Mackinnon, J. (2005). Curso de Derecho Penal. Parte especial, tomo III, Santiago: LexisNexis. 
- Buompadre, J. (2003). Derecho Penal. Parte Especial, 2a ed., Buenos Aires: Mario A. Viera, editor.

- Cadoppi, A. (1996). "Commentario", en Alberto Cadoppi (Coord.): Norme contro la violenza sessuale (legge 15 febbraio 1996), Padova: Edit. Dedam.

- Carmona Salgado (2005). "Delitos contra la libertad e indemnidad sexuales (I)", en Cobo del Rosal (Coord.): Derecho Penal español. Parte especial, Madrid: Dykinson.

- Carnevali, R. (2001). "La mujer como sujeto activo en el delito de violación. Un problema de interpretación teleológica”, Gaceta Jurídica, No 250, abril, pp. 13-18.

- Carrasco Jiménez, E. (2007). "El problema del sujeto activo del delito de violación y sus posibles vacíos legales, Ius et Praxis, año 13, No 2, pp. 137-155.

- Cugat Mauri, M. (2004). "Delitos contra la libertad e indemnidad sexuales”, en Córdoba Roda / García Arán (dirs.): Comentarios al Código Penal. Parte especial, tomo I, Madrid: Marcial Pons.

- Etcheberry, A. (1998). Derecho Penal, tomo III, Santiago: Editorial Jurídica de Chile.

- Fernández Cruz, J. A. (2004). "Una interpretación racional del nuevo artículo 365 bis del Código Penal”, Doctrina Procesal Penal (Colección informes en Derecho, Defensoría Penal Pública).

- Garrido Montt, M. (1998-2005). Derecho Penal. Parte especial, tomo III, Santiago: Editorial Jurídica de Chile.

- González Pérez, J. (1986). La Dignidad de la Persona, Madrid: Civitas.

- Künsemüller, C. (2001). "Nuevas tendencias en el tipo penal de violación”, La Semana Jurídica, No 58, diciembre.

- Maldonado, F. (2005). "Complemento de actualización”, en Garrido Montt, M.: Derecho Penal. Parte especial, tomo III, Santiago: Editorial Jurídica de Chile.

- Mercado Gómez, M. A. (2003). Problemas concursales y delito continuado en los delitos que protegen la libertad sexual, Santiago: LexisNexis.

- Monge Fernández, A. (2005). Los delitos de agresiones sexuales violentas, Valencia: Tirant lo Blanch.

- Nogueira Alcalá, H. (1995). "Dignidad de la persona y derechos humanos: Constitución, tratados y ley de amnistía”, en VV. AA: La Dignidad de la Persona, Actas de las XXV Jornadas Chilenas de Derecho Público, tomo II, Valparaíso: Edit. Edeval.

- Orts Berenguer, E. / Suárez-Mira Rodríguez, C. (2001). Los delitos contra la libertad e indemnidad sexuales, Valencia: Tirant lo Blanch.

- Picotti, L. (1996). "Il delito sessuale: ...Spinti di reflessione sull'evoluzione e la riforma dei reati sessuali”, en Alberto Cadoppi 
(Coord.): Norme contro la violenza sessuale (legge 15 febbraio 1996), Padova: Edit. Dedam.

- Politoff, S. / Matus, J. P. / Ramírez, M. C. (2005). Lecciones de derecho penal. Parte especial, 2a ed., Santiago: Editorial Jurídica de Chile.

- Rodríguez Collao, L. (2004). Delitos sexuales, Santiago: Editorial Jurídica de Chile. (2008). "La figura cualificada de abuso sexual del artículo 365 bis del Código Penal", en VV. AA: Delito, pena y proceso. Libro homenaje a la memoria del profesor Tito Solari Peralta. Santiago: Editorial Jurídica de Chile, pp. 357-380.

- Rodríguez Collao, L. / De la Fuente, F. (1990): "El principio de culpabilidad en la Constitución de 1980", Revista de Derecho, Pontificia Universidad Católica de Valparaíso (Chile), No 13.

- Ruiz-Giménez Cortés, J. (1984). "Comentarios al artículo 10 de la Constitución”, en Alzaga Villaamil, O. (dir.): Comentarios a las Leyes Políticas, tomo II, Madrid: Edersa.

- Ruiz Miguel, C. (1995). "El significado jurídico del principio de la dignidad de la persona en el ordenamiento español", en VV. AA: La Dignidad de la Persona, Actas de las XXV Jornadas Chilenas de Derecho Público, Valparaíso: Edeval.

- Sánchez Agesta, L. (1980). El Sistema Político de la Constitución Española de 1978, Madrid: Editora Nacional.

- Serrano Gómez / Serrano Maíllo (2006). Derecho Penal. Parte especial, $11^{\text {a }}$ ed., Madrid: Dykinson. 